\title{
BMJ Open The feasibility of meeting the WHO guidelines for sodium and potassium: a cross-national comparison study
}

\author{
Adam Drewnowski, ${ }^{1,2}$ Colin D Rehm, ${ }^{1,3}$ Matthieu Maillot, ${ }^{4}$ Alfonso Mendoza, ${ }^{1,5}$ \\ Pablo Monsivais ${ }^{6}$
}

To cite: Drewnowski A, Rehm CD, Maillot M, et al. The feasibility of meeting the WHO guidelines for sodium and potassium: a crossnational comparison study. BMJ Open 2015;5:e006625. doi:10.1136/bmjopen-2014006625

- Prepublication history for this paper is available online. To view these files please visit the journal online (http://dx.doi.org/10.1136/ bmjopen-2014-006625)

Received 15 September 2014 Revised 28 October 2014 Accepted 30 October 2014

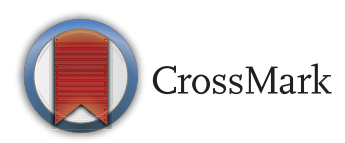

For numbered affiliations see end of article.

Correspondence to Dr Adam Drewnowski; adamdrew@uw.edu

\section{ABSTRACT}

Objective: To determine joint compliance with the WHO sodium-potassium goals in four different countries, using data from nationally representative dietary surveys. Setting: Compared to national and international recommendations and guidelines, the world's population consumes too much sodium and inadequate amounts of potassium. The WHO recommends consuming less than $2000 \mathrm{mg}$ sodium $(86 \mathrm{mmol}$ ) and at least $3510 \mathrm{mg}$ potassium $(90 \mathrm{mmol})$ per person per day.

Participants: Dietary surveillance data were obtained from the National Health and Nutrition Examination Survey (NHANES 2007-2010) for the USA; the Encuesta Nacional de Salud y Nutrición 2012 for Mexico; the Individual and National Study on Food Consumption (INCA2) for France; and the National Diet and Nutrition Survey (NDNS) for the UK.

Primary outcome measures: We estimated the proportion of adults meeting the joint WHO sodiumpotassium goals in the USA, the UK, France and Mexico.

Results: The upper bounds of joint compliance with the WHO sodium-potassium goals were estimated at $0.3 \%$ in the USA, $0.15 \%$ in Mexico, $0.5 \%$ in France and $0.1 \%$ in the UK.

Conclusions: Given prevailing food consumption patterns and the current food supply, implementing WHO guidelines will be an enormous challenge for global public health.

\section{INTRODUCTION}

Compared to international and national recommendations and guidelines, the world's population consumes too much dietary sodium and inadequate amounts of potassium. ${ }^{1-4}$ Excessive sodium consumption and excessively high dietary sodium-potassium ratios have been linked to a higher risk of cardiovascular disease (CVD), including coronary heart disease and stroke.$^{5-7}$ Annually, 1.65 million deaths from cardiovascular disease, or about $10 \%$ of cardiovascular deaths, could be attributed to excess sodium intake, globally. ${ }^{8}$

Preventing non-communicable diseases is a top priority for global public health. ${ }^{1-3}$

\section{Strengths and limitations of this study}

- The present data represent the best source of information on the dietary habits of a large and nationally representative sample of adults in each country.

- Each of the data sets analysed is a flagship national study that informs a nation's food and nutrition policy and provides data to be furnished to the WHO.

- Different dietary surveys used different methodologies and nutrient composition databases.

- Analyses were based on a limited number of days, which may not capture habitual intakes.

- All nutrient intakes were based on self-reports and were subject to reporting errors that may result in under-estimating the consumption of sodium. In addition, sodium intakes from table salt and supplements were not included.

The WHO has recommended consuming less than $2000 \mathrm{mg}$ of sodium, or $5 \mathrm{~g}$ of salt, and consuming at least $3510 \mathrm{mg}$ of potassium per day. ${ }^{3}$ These amounts are equivalent to $86 \mathrm{mmol}$ sodium and $90 \mathrm{mmol}$ potassium, making for a desirable dietary sodium-potassium ratio of approximately 1.0. ${ }^{9}$

Current consumption levels are vastly different. ${ }^{9}{ }^{10}$ Median sodium intakes in the USA among adults were estimated at $3371 \mathrm{mg}$ /day, while potassium intakes were estimated at $2631 \mathrm{mg} /$ day. ${ }^{11}$ Relative to recommended values of 2300 and $1500 \mathrm{mg} /$ day for sodium, $90.7 \%$ and $99.4 \%$ consumed excess sodium, respectively, while only $1.4 \%$ consumed more than $4700 \mathrm{mg} /$ day of potassium. Sodium intakes in the UK and France were $>50 \%$ above the WHO recommended values. ${ }^{12} 13$ Assessments of urinary-based measures of sodium paint a similarly dire picture; estimates show that global intakes are approximately $3950 \mathrm{mg} /$ day, nearly twice the recommended value. ${ }^{4}$ In no region did average sodium intakes fall below $2000 \mathrm{mg} /$ day. ${ }^{4}$

Reducing sodium while simultaneously increasing potassium intakes presents 
multiple challenges. ${ }^{14} 15$ First, sodium and potassium intakes are closely tied to energy balance, such that persons with higher energy requirements consume more potassium but also more sodium. ${ }^{16}$ Very low sodium diets tend to be low in calories and may not provide adequate nutrition. ${ }^{15}$ Uncoupling sodium from dietary potassium can be problematic, since both are present in many of the same foods. ${ }^{17}$ In mathematical models based on dietary intakes from the National Health and Nutrition Examination Survey (NHANES), the US sodium and potassium guidelines appeared to be incompatible with each other. ${ }^{14}$ In empirical analyses of the 2003-2008 NHANES data, joint compliance with the published US sodium-potassium guidelines (1500 mg sodium and $4700 \mathrm{mg}$ potassium) was estimated between 0 and $0.015 \% .^{16}$

We now examined joint compliance with the new WHO sodium and potassium guidelines in four different countries, using nationally representative databases. Since the WHO guidelines ${ }^{1-3}$ have an intended global reach, examining sodium and potassium intakes in more than one country is of particular interest. Assessing the feasibility of dietary recommendations and guidelines is a critical component of global public health policy.

\section{METHODS}

Data on sodium and potassium intakes were obtained from publicly available national dietary surveys for the US, Mexico, France and the UK. Each of those studies was approved by institutional review boards in their respective countries. Detailed procedures for data collection have been published previously and are noted below.

The National Health and Nutrition Examination Survey (NHANES 2007-2010) is a nationally representative survey of the US population. ${ }^{18}$ The present analyses were based on 9720 adults aged $\geq 20$ years with two complete and valid $24 \mathrm{~h}$ recalls. For each survey participant, sodium and potassium intakes were obtained from the mean of two non-consecutive $24 \mathrm{~h}$ recalls. Although two dietary recalls do not reflect true estimates of habitual intake, they do provide an upper bound of the proportion of the population meeting sodium and potassium goals.

The Encuesta Nacional de Salud y Nutrición 2012 (ENSANUT 2012) in Mexico is based on a random representative sample of children and adults. ${ }^{19}$ Dietary intake data are based on a semiquantitative and previously validated 7-day food frequency questionnaire. ${ }^{20}$ The present analyses were based on adults aged $\geq 20$ only $(n=2879)$. The databases and documentation of protocols are available online. ${ }^{19}$

The Individual and National Study on Food Consumption (INCA2) in France is based on a nationally representative sample of 1455 children ages 3-17 years and 2624 adults aged $18-79$ years. The study was conducted by the ANSES government agency (Agence nationale de sécurité sanitaire de l'alimentation, de l'environnement et du travail). ${ }^{12}$ Dietary intake data were based on 7-day food diaries, aided by a photographic atlas of portion sizes. The present analyses were based on adults aged $\geq 20$ years only, excluding under and over reporters $(\mathrm{n}=1726)$.

The National Diet and Nutrition Survey (NDNS) in the UK is a nationally representative sample of UK residents aged 1.5 years and older, stratified by age and gender. The survey recruits 1000 participants per year, children as well as adults. ${ }^{21}$ Data analysed in this study were for years 1-3 of the rolling programme, with 4-day food diaries available for 3073 individuals. The present analyses were based on a sample of 1472 adults. Further details on sampling, data collection and processing are published. ${ }^{21}$

The proportion of persons meeting the sodium and potassium guidelines, separately and jointly, was calculated. ${ }^{16}$ Survey weighted medians and 25th and 75th centiles for sodium and potassium intakes were calculated for each survey sample. All analyses of NHANES data were conducted using Stata V.13.0 (College Station, Texas, USA), accounting for the complex survey design.

\section{RESULTS}

Figure 1 shows the distributions of individual intakes of sodium and potassium as scatterplots, separately for each country. The top left panel shows mean 2-day sodium and potassium intakes for US adults aged $\geq 20$ years in 2007-2010 NHANES. The figure was cropped to exclude potassium intakes of $>6000 \mathrm{mg} /$ day $(\mathrm{n}=87$ adults $)$ and sodium intakes of $>8000 \mathrm{mg} /$ day ( $\mathrm{n}=99$ adults). As indicated by solid lines, $86.2 \%$ of the sample failed to meet the WHO sodium goal $(95 \%$ CI 84.9 to 87.4 ) and $80.4 \%$ failed to meet the WHO potassium goal (95\% CI 79.1 to 81.7 ). The upper bound of joint compliance with the WHO sodium-potassium goals was estimated at $0.3 \%$ (95\% CI 0.2 to 0.5 ).

Figure 1 (top right panel) shows estimated sodium and potassium intakes for 2879 Mexican adults aged $\geq 20$ years in the 2012 ENSANUT. As indicated, 44\% failed to meet the WHO sodium goal (95\% CI $41 \%$ to $47.2 \%$ ) and $95 \%$ failed to meet the WHO potassium goal (95\% CI $93.4 \%$ to $96.2 \%)$. Joint compliance with WHO sodium-potassium goals was estimated at $0.15 \%$ (95\% CI $0.04 \%$ to $0.5 \%$ ).

Figure 1 (bottom left panel) shows estimated sodium and potassium intakes for 1726 French adults aged $\geq 20$ years in the INCA 2 study. As indicated, $89.1 \%$ failed to meet the WHO sodium goal (95\% CI 87.2 to $90.8 \%$ ) and $77 \%$ failed to meet the potassium goal (95\% CI 74.5 to $79.3 \%)$. Joint compliance with both WHO goals was estimated at $0.5 \%$ (95\% CI 0.2 to 1.0 ).

Mean sodium and potassium intakes for 1472 UK adults aged $\geq 20$ years in the NDNS study year are shown in figure 1 (bottom right panel). As indicated, 83.4\% failed to meet the sodium goal (95\% CI 81.3 to 85.5 ) and $91.9 \%$ failed to meet the potassium goal $(95 \%$ CI 
Figure 1 Distribution of sodium ( $x$ axis) and potassium intakes (y axis) in four countries relative to WHO sodium-potassium goals. The proportion of the population meeting the joint goals is shown in the top left hand quadrant of each panel.
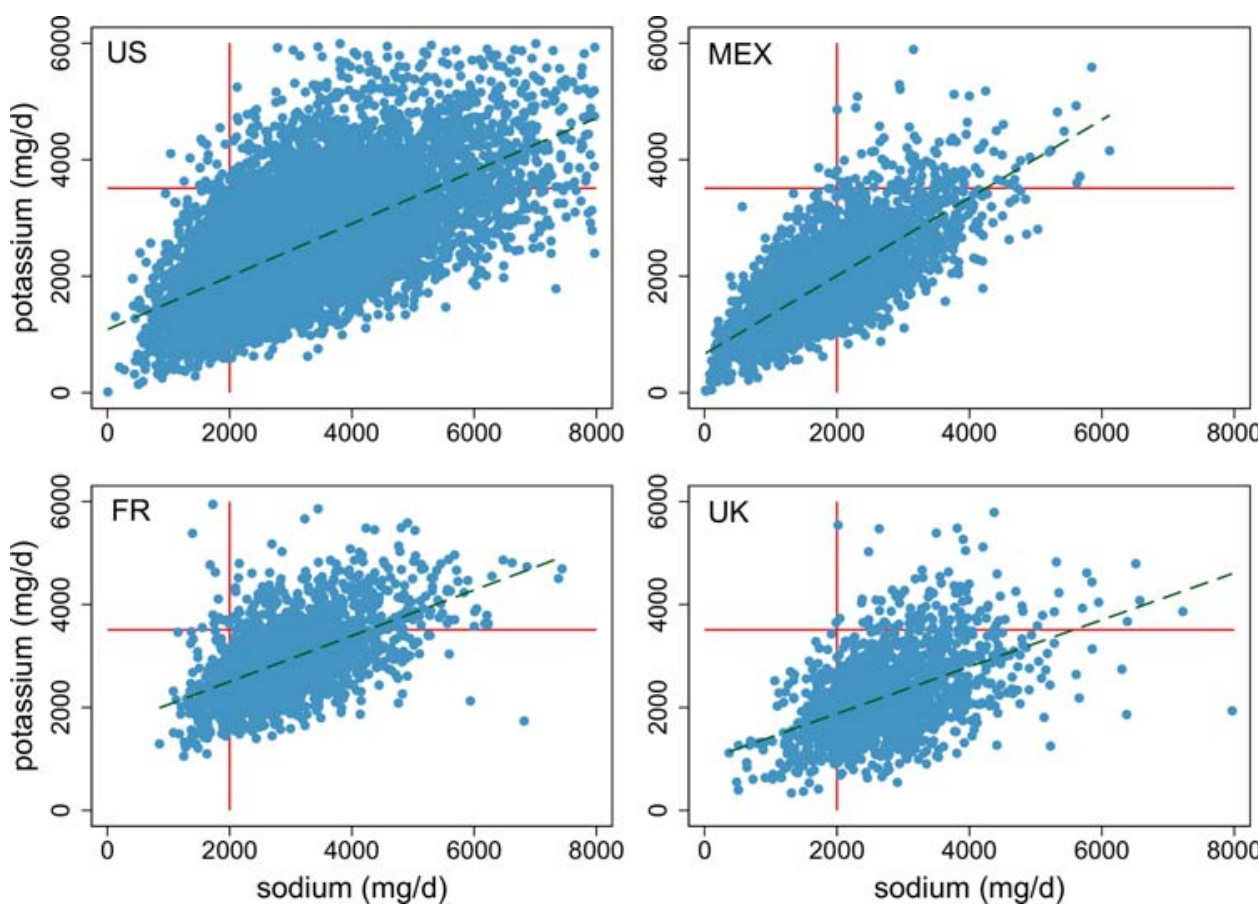

90.2 to 93.4$)$. Joint compliance with both WHO goals was estimated at $0.1 \%(95 \%$ CI 0.02 to 0.9$)$.

Figure 2 shows the relation between the WHO sodium-potassium goals and survey-weighted medians and IQRs for each country.

\section{DISCUSSION}

This is the first analysis of the feasibility of the WHO joint goals, based on nationally representative dietary data from four countries. How the sodium and potassium goals are determined illustrates the complexities of

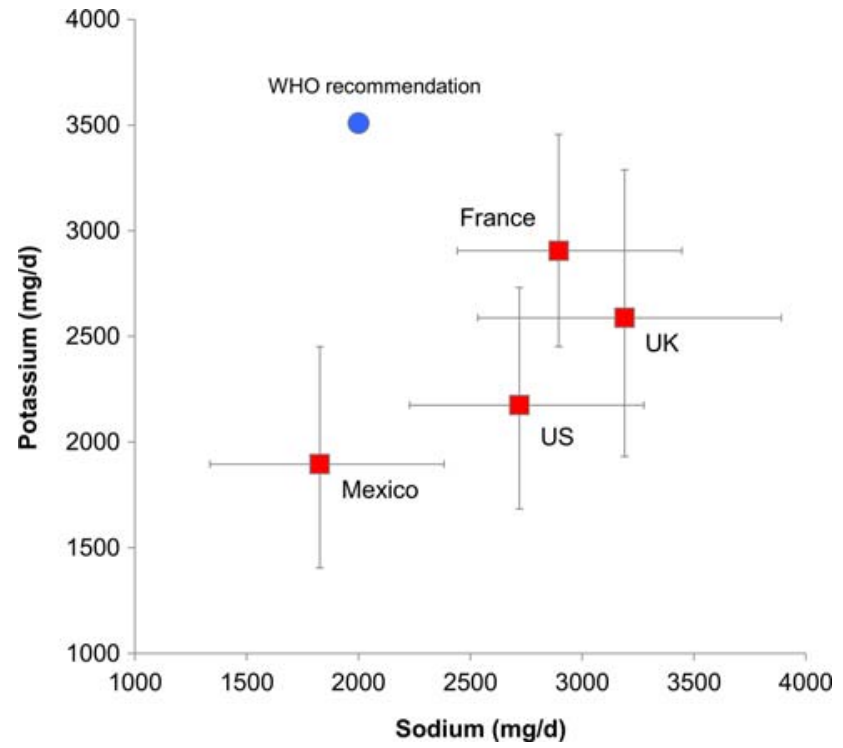

Figure 2 Relation between WHO recommendations and survey-weighted medians for sodium and potassium intakes for the four countries. Error bars correspond to IQR (25th and 75th centile). translating science into public policy. The WHO global goals were based on the levels recommended by the 2002 joint WHO/FAO Expert Consultation and adopted by the WHO guidelines for CVD prevention. ${ }^{22}$

The 2010 US Dietary Guidelines set sodium targets at $2300 \mathrm{mg} /$ day for the general population, with a lower goal of $1500 \mathrm{mg}$ /day for certain subgroups at risk. ${ }^{10}$ The $1500 \mathrm{mg} /$ day target was initially suggested by the Institute of Medicine (IOM) expert committee; however, issues were later raised about health benefits and likely compliance. ${ }^{23}$ Since then, the IOM has concluded that the evidence for the health benefits associated with sodium intakes $<2300 \mathrm{mg} /$ day was lacking. ${ }^{23}{ }^{24}$ Noting that very low sodium intakes may also increase health risks-particularly in certain groups-the IOM report reaffirmed the $2300 \mathrm{mg}$ /day sodium goal for the general population. ${ }^{23} 24$

That report was criticised by the American Heart Association (AHA) as being incomplete, and AHA continues to recommend consuming less than 1500 mg/day. ${ }^{25} 26$ The 2010 Dietary Guidelines for Americans, which currently informs federal efforts regarding sodium intakes, recommends a sodium goal of $1500 \mathrm{mg} /$ day for persons aged $>50$ years, African-Americans, and persons with diabetes, hypertension and chronic kidney disease. ${ }^{10} 27$ Given the considerable discussion regarding these recommendations, the recommendations of the 2015 Dietary Guidelines for Americans Advisory Committee for sodium will be met with much anticipation. There has been much less debate regarding potassium goals, which remained at a relatively high $4700 \mathrm{mg} /$ day, when compared to current levels of dietary potassium. ${ }^{10}$

The French Recommended Dietary Allowances (Apports Nutritionnels Conseillés, or ANG) set salt the consumption target in the 5-8 g/day range, equivalent to 2000- 
$3200 \mathrm{mg} /$ day of sodium. The potassium target was set at $3100 \mathrm{mg} /$ day. The UK agency NICE has set UK sodium target at $<2360 \mathrm{mg}$ /day of sodium per adult by year 2015 , to be reduced further to a very low $<1180 \mathrm{mg} /$ day of sodium by 2025. ${ }^{913}{ }^{28}$ Potassium targets were not specified. The Pan American Health Organisation (PAHO) has been making signal efforts at sodium reduction in the Americas and is likely to follow the WHO lead on sodium and potassium goals, as is Mexico.

The present analyses, based on nationally representative studies, suggest that joint compliance with the published WHO sodium and potassium goals is close to zero. These conclusions are consistent with published analyses of the NHANES data by the Centers for Disease Control, which estimated that only $0.6 \%$ of the population met the $1500 \mathrm{mg} /$ day sodium goal and $1.4 \%$ met the goal for potassium. ${ }^{11}$ The upper bounds of joint compliance with sodium-potassium, based on the same NHANES data, were estimated by us at $0.015 \%$ for $1500 \mathrm{mg}$ /day sodium and at $0.12 \%$ for $2300 \mathrm{mg} /$ day sodium. ${ }^{16}$

Given the surprisingly low levels of compliance with global goals, it is clear that purely educational and individual-level approaches to sodium reduction are unlikely to be successful. Reducing sodium in the food supply through thorough reformulation of processed and packaged foods, as well as by making parallel efforts to reduce the sodium content of foods prepared away from home, are the most promising strategies to reduce population-wide sodium exposure. ${ }^{29} 30$ The largest contributors of sodium in the diet depend on food classifications evaluated, but yeast breads, pizza, processed meats, cheese and meat/poultry mixed dishes, are among the most important sources of dietary sodium in the USA. ${ }^{31}{ }^{32}$ Processed foods, including breads, cereals and grains, contribute a majority of sodium in the UK and in France as well. ${ }^{12} 33$ It is important to note that frequency of consumption, rather than sodium density (eg, sodium per serving or per calorie), is the most important determinant of population-wide sodium reduction. Therefore, reformulation efforts, whether voluntary or mandated, should focus on the largest sources of sodium population-wide rather than the most sodium-rich products.

On the other hand, increasing potassium intakes cannot be achieved through reformulation. As in sodium, the most important sources of potassium are frequently consumed foods, including milk, coffee, mixed meat/ chicken dishes, fruit juices and potatoes in the USA, and dairy products, vegetables and meats in France. ${ }^{12} 34$ Achieving adequate potassium intakes will likely require increasing the consumption of less frequently consumed potassium-rich foods, including beans, dark-green vegetables, dried fruits and fish. While simultaneously decreasing sodium and increasing potassium should be the long-term goal for populations, independently increasing potassium intakes in diets will also likely have numerous benefits. $^{35-37}$
Perceived or actual food costs may be one reason why the observed sodium-potassium ratio is excessively high. ${ }^{38}$ Merging dietary intakes from the 2001 to 2002 NHANES with a national food price database showed that more favourable sodium-potassium ratios were associated with higher per calorie diet costs. ${ }^{17} 39$ The difference in diet cost among participants with highest and lowest potassium intakes was $\$ 1.49 /$ day (95\% CI 1.29 to 1.69 ), comparable to the $\$ 1.50 /$ day amount associated with healthier diets from a recent meta-analysis of diet cost studies. ${ }^{17}{ }^{40} \mathrm{No}$ association was observed between diet cost and sodium. These results suggest that, under current eating patterns, increasing potassium intakes may incur increasing dietary costs, while decreasing sodium intakes can likely be achieved in a cost neutral manner.

Calorie-indexed dietary guidelines could also help. Population-wide sodium and potassium goals continue to be framed in $\mathrm{mg}$ per person per day, regardless of individual energy needs. ${ }^{14} 15$ Persons with high energy intakes may be able to meet potassium but not sodium goals; whereas persons with low energy intakes may meet sodium goals but have inadequate potassium, as sodium and potassium are both highly correlated with dietary energy. One way to address this issue may be to tie sodium and potassium goals to energy requirements. Such a nutrient indexing model was proposed in 1999 for the Dietary Approaches to Stopping Hypertension (DASH) $\operatorname{diet}^{41}$ and, more recently, by ANSES in France. ${ }^{12}$ Another approach would be to focus dietary guidance on the sodium-potassium ratio, currently much higher than the recommended target of $1.0 .^{6}$

The present analysis of the multinational data sets has several limitations. First, the different dietary surveys used different methodologies, including dietary recalls (US), food diaries/records (UK and France) and a food frequency questionnaire (Mexico). Second, analyses were based on a limited number of days for those data derived from dietary recalls and food diaries, which may not capture habitual intakes. This is particularly a concern for the US data where a two-day average was used. Advanced methods are available to estimate habitual intakes based on dietary recalls for a single dietary constituent, though methods for estimating joint compliance based on habitual intakes have not been developed. As a result, our population estimates represent an upper bound of the compliance to sodium, potassium and the joint goals. Third, all nutrient intakes were based on selfreports and were subject to reporting errors that may result in under-estimating the consumption of sodium, due to omission of sodium-dense foods or potential overreporting of potassium intakes, such as fruits/vegetables. Fourth, sodium intakes from table salt and supplements were not included. Lastly, the nutrient composition databases used by different countries may differ in quality. Despite these limitations, the present data represent the best source of information on the dietary habits of a large and nationally representative sample of adults in each country. Each of the data sets analysed is a flagship 
national study that informs that nation's food and nutrition policy and provides data to be furnished to the WHO.

There is a case to be made for more feasibility research in the formulation of public policy. First, the fact that the proposed WHO guidelines are very far removed from current patterns of intake in multiple countries should be an indication of potential problems ahead. Dealing with this level of non-compliance will be a challenge for global public health practice. Second, dietary guidelines need to suggest ways of meeting recommendations without substantially increasing diet costs. Third, given globalisation of science, expertise and access to data should be readily available. Yet different countries have different guidelines for sodium and potassium that do not necessarily correspond to those issued by the WHO. Better harmonisation of dietary goals would aid in the implementation of global food and nutrition policies.

\section{Author affiliations}

${ }^{1}$ Center for Public Health Nutrition, University of Washington, Seattle, Washington, USA

${ }^{2}$ Institute for Cardiometabolism and Nutrition (ICAN), Université Pierre et Marie Curie Paris VI, Groupe Hospitalier Pitié-Salpetrière, Paris, France ${ }^{3}$ Friedman School of Nutrition Science and Policy, Tufts University, Boston, Massachusetts, USA

${ }^{4}$ MS-Nutrition SAS, Marseille, France

${ }^{5}$ Departamento de Ciencias Sociales, Centro de Investigación e Inteligencia Económica, Universidad Popular Autónoma del Estado de Puebla, Puebla, Mexico

${ }^{6}$ The Centre for Diet and Activity Research (CEDAR), University of Cambridge, Cambridge, UK

Contributors $A D$ and $C D R$ designed and conducted the research. CDR, MM, $A M$ and PM provided the data. CDR, MM, AM and PM analysed the data. AD, CDR and PM wrote the paper. AD had primary responsibility for final content All authors read and approved the final manuscript.

Funding Supported by NIH grants R01 DK 077068-04 and R21 DK085406. PM was supported by the Centre for Diet and Activity Research, a UKCRC Public Health Research Centre of Excellence. Funding from the British Heart Foundation, Cancer Research UK, Economic and Social Research Council, Medical Research Council, the National Institute for Health Research, and the Wellcome Trust, under the auspices of the UK Clinical Research Collaboration, is gratefully acknowledged.

Competing interests $A D$ has received grants, honoraria and consulting fees from numerous food and beverage companies and other commercial and non-profit entities with interests in diets and health. The University of Washington has received grants, donations and contracts from the public as well as the private sector. CDR, MM, AM and PM have no conflicts to declare.

Provenance and peer review Not commissioned; externally peer reviewed.

Data sharing statement Data on sodium and potassium intakes were obtained from publicly available national dietary surveys for the US (National Health and Nutrition Examination Survey (NHANES 2007-2010)), Mexico (Encuesta Nacional de Salud y Nutrición 2012 (ENSANUT 2012)), France (Individual and National Study on Food Consumption (INCA2)) and the UK (National Diet and Nutrition Survey (NDNS)).

Open Access This is an Open Access article distributed in accordance with the terms of the Creative Commons Attribution (CC BY 4.0) license, which permits others to distribute, remix, adapt and build upon this work, for commercial use, provided the original work is properly cited. See: http:// creativecommons.org/licenses/by/4.0/

\section{REFERENCES}

1. World Health Organization. Guideline: sodium intake for adults and children. http://www.who.int/nutrition/publications/guidelines/sodium_ intake_printversion.pdf (accessed Jul 2014).

2. World Health Organization. Guideline potassium intake for adults and children. http://apps.who.int/iris/bitstream/10665/77986/1/ 9789241504829_eng.pdf?ua=1 (accessed Jul 2014).

3. World Health Organization. WHO issues new guidance on dietary salt and potassium. http://www.who.int/mediacentre/news/notes/ 2013/salt_potassium_20130131/en/ (accessed Jul 2014).

4. Powles J, Fahimi S, Micha R, et al. Global, regional and national sodium intakes in 1990 and 2010: a systematic analysis of 24h urinary sodium excretion and dietary surveys worldwide. BMJ Open 2013;3:e003733.

5. Appel LJ, Frohlich ED, Hall JE, et al. The importance of population-wide sodium reduction as a means to prevent cardiovascular disease and stroke: a call to action from the American Heart Association. Circulation 2011;123:1138-43.

6. Cook NR, Obarzanek E, Cutler JA, et al. Joint effects of sodium and potassium intake on subsequent cardiovascular disease: the Trials of Hypertension Prevention follow-up study. Arch Intern Med 2009;169:32-40.

7. Yang Q, Liu T, Kuklina EV, et al. Sodium and potassium intake and mortality among US adults: prospective data from the Third National Health and Nutrition Examination Survey. Arch Intern Med 2011;171:1183-91.

8. Mozaffarian D, Fahimi S, Singh GM, et al. Global sodium consumption and death from cardiovascular causes. N Engl J Med 2014;371:624-34

9. The BMJ. Reducing salt and increasing potassium will have major global health benefits. http://www.bmj.com/press-releases/2013/04/ 04/reducing-salt-and-increasing-potassium-will-have-major-globalhealth-benef (accessed Jul 2014).

10. U.S. Department of Agriculture, U.S. Department of Health and Human Services. Dietary Guidelines for Americans, 2010. 7th edn. Washington, DC: U.S. Government Printing Office, 2010.

11. Cogswell ME, Zhang Z, Carriquiry AL, et al. Sodium and potassium intakes among US adults: NHANES 2003-2008. Am J Clin Nutr 2012:96:647-57.

12. Meneton P, Lafay L, Tard A, et al. Dietary sources and correlates of sodium and potassium intakes in the French general population. Eur J Clin Nutr 2009:63:1169-75.

13. UK Department of Health. Salt Reduction 2017. https:// responsibilitydeal.dh.gov.uk/pledges/pledge/?pl=49 (accessed Jul 2014).

14. Maillot M, Monsivais $\mathrm{P}$, Drewnowski A. Food pattern modeling shows that the 2010 Dietary Guidelines for sodium and potassium cannot be met simultaneously. Nutr Res 2013;33:188-94.

15. Maillot M, Drewnowski A. A conflict between nutritionally adequate diets and meeting the 2010 dietary guidelines for sodium. Am J Prev Med 2012;42:174-9.

16. Drewnowski A, Maillot M, Rehm C. Reducing the sodium-potassium ratio in the US diet: a challenge for public health. Am J Clin Nutr 2012;96:439-44.

17. Drewnowski A, Rehm CD, Maillot M, et al. The relation of potassium and sodium intakes to diet cost among US adults. J Hum Hypertens 2014;29:14-21.

18. Haines DJ, Davis L, Rancour $\mathrm{P}$, et al. A pilot intervention to promote walking and wellness and to improve the health of college faculty and staff. J Am Coll Health 2007:55:219-25.

19. Rodriguez-Ramirez S, Mundo-Rosas V, Jimenez-Aguilar A, et al. Methodology for the analysis of dietary data from the Mexican National Health and Nutrition Survey 2006. Salud Publica Mex 2009;51(Suppl 4):S523-9.

20. Hernandez-Avila M, Romieu I, Parra S, et al. Validity and reproducibility of a food frequency questionnaire to assess dietary intake of women living in Mexico City. Salud Publica Mex 1998:40:133-40.

21. Timmins KA, Hulme C, Cade JE. The monetary value of diets consumed by British adults: an exploration into sociodemographic differences in individual-level diet costs. Public Health Nutr 2013:1-9.

22. World Health Organization. Prevention of cardiovascular disease: guidelines for assessment and management of cardiovascular risk http://www.who.int/cardiovascular_diseases/guidelines/Fulltext.pdf (accessed Jul 2014).

23. Institute of Medicine. Sodium intake in populations: assessment of evidence. http://www.iom.edu/Reports/2013/Sodium-Intake-inPopulations-Assessment-of-Evidence/Report-Brief051413.aspx (accessed Jul 2014). 
24. National Academies. Studies support population-based efforts to lower excessive dietary sodium intakes, but raise questions about potential harm from too little salt intake. http://www8. nationalacademies.org/onpinews/newsitem.aspx?RecordID=18311 (accessed Jul 2014)

25. American Heart Association. New IOM report an incomplete review of sodium's impact, says American Heart Association. http://newsroom. heart.org/news/new-iom-report-an-incomplete-review-of-sodiumsimpact-says-american-heart-association (accessed Jul 2014).

26. Hagihara A, Tarumi K, Nobutomo K. Grouping participants for tailored work-site weight loss programs: a signal detection approach. Am J Ind Med 2002;41:269-78.

27. Centers for Disease Control and Prevention (CDC). Most Americans should consume less sodium. http://www.cdc.gov/salt/ (accessed Jul 2014).

28. Consensus Action on Salt \& Health. NICE public health guidance: prevention of cardiovascular disease. http://www.actiononsalt.org.uk salthealth/Recommendationsonsalt/42503.html (accessed Jul 2014).

29. Health Canada Report. Guidance for the food industry on reducing sodium in processed foods. http://www.worldactiononsalt.com/docs/ world/78296.pdf (accessed Jul 2014).

30. Rehm CD, Drewnowski A. A new method to monitor the contribution of fast food restaurants to the diets of US children. PLoS One 2014;9:e103543.

31. Drewnowski A, Rehm CD. Sodium intakes of US children and adults from foods and beverages by location of origin and by specific food source. Nutrients 2013;5:1840-55.

32. Centers for Disease Control, Prevention. Vital signs: food categories contributing the most to sodium consumption-United States, 2007-2008. MMWR Morb Mortal Wkly Rep 2012;61:92-8.
33. Anderson CA, Appel LJ, Okuda N, et al. Dietary sources of sodium in China, Japan, the United Kingdom, and the United States, women and men aged 40 to 59 years: the INTERMAP study. J Am Diet Assoc 2010;110:736-45.

34. Guico-Pabia CJ, Cioffi L, Shoner LG. The Lucent-Takes-Heart cardiovascular health management program. Successful workplace screening. AAOHN J 2002;50:365-72.

35. Seth A, Mossavar-Rahmani Y, Kamensky V, et al. Potassium intake and risk of stroke in women with hypertension and nonhypertension in the Women's Health Initiative. Stroke 2014;45: 2874-80.

36. Aburto $\mathrm{NJ}$, Hanson $\mathrm{S}$, Gutierrez $\mathrm{H}$, et al. Effect of increased potassium intake on cardiovascular risk factors and disease: systematic review and meta-analyses. BMJ 2013;346:f1378.

37. D'Elia L, Barba G, Cappuccio FP, et al. Potassium intake, stroke, and cardiovascular disease a meta-analysis of prospective studies. J Am Coll Cardiol 2011;57:1210-19.

38. Monsivais $\mathrm{P}$, Aggarwal A, Drewnowski A. Following federal guidelines to increase nutrient consumption may lead to higher food costs for consumers. Health Aff (Millwood) 2011;30:1471-7.

39. Monsivais $\mathrm{P}, \mathrm{Rehm}$ CD, Drewnowski A. The DASH diet and diet costs among ethnic and racial groups in the United States. JAMA Intern Med 2013;173:1922-4.

40. Rao M, Afshin A, Singh G, et al. Do healthier foods and diet patterns cost more than less healthy options? A systematic review and metaanalysis. BMJ Open 2013;3:e004277.

41. Lin PH, Windhauser MM, Plaisted CS, et al. The Linear Index Model for establishing nutrient goals in the Dietary Approaches to Stop Hypertension trial. DASH Collaborative Research Group. J Am Diet Assoc 1999;99:S40-4. 